\title{
CARACTERIZAÇÃO MORFOMÉTRICA DA BACIA HIDROGRÁFICA DO RIBEIRÃO CACHOEIRA, MT-BRASIL
}

Osvaldo Borges Pinto Junior ${ }^{1}$, Amintas Nazareth Rossete ${ }^{1} .(1$ - Universidade do Estado de Mato Grosso (UNEMAT) - Campus de Nova Xavantina - Br-158, Km-146, Caixa Postal 08 Nova Xavantina - MT - CEP.: 78690-000 osvaldo.borges@gmail.com, amnrote@,uol.com.br)

\section{RESUMO}

Nos estudos de bacia hidrográfica, a mensuração e a análise matemática da configuração da superfície terrestre, quanto à forma e às dimensões de sua paisagem, são usadas nas estimativas das características da Bacia Hidrografia (morfometria). Este trabalho teve como objetivo quantificar os parâmetros morfométricos e construir um modelo digital de terreno da Bacia Hidrográfica do Ribeirão Cachoeira. A bacia fica localizada entre os Municípios de Campinápolis e Nova Xavantina, com aproximadamente $359,81 \mathrm{Km}^{2}$. A metodologia baseouse no uso de Imagens de Satélite, cartas topográficas e Softwares especializados, como o Idrisi, AutoCad e Surfer, sendo possível calcular índices morfométricos variados. De acordo com os valores calculados a Bacia Hidrográfica do Ribeirão Cachoeira é do tipo dendrítica. Este tipo de drenagem reflete características como a presença de solos homogêneos e rochas sedimentares. A bacia fica também caracterizada, por conter dois grandes compartimentos, a Bacia Hidrográfica do Córrego Cachoeira e a Sub-Bacia do Córrego Voadeira. Com os resultados dos índices morfométricos, foi possível evidenciar que a bacia é composta por rochas areníticas (forma das drenagens), com grande capacidade de gerar novos cursos d'água, pois apresenta uma área relativamente apropriada para a manutenção de seus canais de drenagem, a área apresenta relevo e índice de sinuosidade irregulares, determinados mais pelo tipo de carga dendrítica do que pela própria descarga fluvial.

Palavras-chave: Morfometria, Bacia Hidrográfica, Ribeirão Cachoeira.

\section{ABSTRACT}

\section{Morphometric characterization of the hydrographic basin in Ribeirão Cachoeira-Brazil}

The morphometrics studies comprise the measurement and mathematical analyses of the land surface configuration, as well as the shape and dimensions of its landscape, and it is used to estimate the watershed characteristics. This objective of this work was to quantify the 
morphometrics parameters and to build a digital elevation model of the drainage basin of Cachoeira stream. This drainage basin is located between Campinápolis and Nova Xavantina municipalities, with an area of approximately $359,81 \mathrm{~km}^{2}$. The methodology was based in the use of satellites images, topographical charts, and specialized softwares, as Idrisi, AutoCad and Surfer, through which was possible to calculate varied morphometric indexes. According to the calculated values, the drainage basin of Cachoeira stream presents a dendritic pattern. This drainage pattern reflects some characteristics as the presence of homogeneous soils and sedimentary rocks. The drainage basis is also characterized for containing two large compartments, the drainage basin of Cachoeira stream and the sub-drainage basin of the Voadeira stream. The results of the morphometrics indexes demonstrate that the drainage basin is composed of arenitic rocks (drainage shape), so it presents great capacity to originate new water courses, since this is a relatively good area for the maintenance of the drainage channels. The area presents irregular relief and sinuosity index, much more determined by the type of dendritic load than by the fluvial discharge.

Word-key: Morphometry, hydrographic basin, River Cachoeira.

\section{Introdução}

Os estudos relacionados com as bacias hidrográficas e suas redes de drenagem sempre mereceram atenção da geomorfologia por terem papel fundamental na esculturação do modelo terrestre. Diferentes trabalhos (HORTON, 1945; LANA, 2001; STHALLER, 1957 e CUNHA E GUERRA, 1996) têm demonstrado que as direções preferenciais dos fluxos superficiais definem os mecanismos erosivo-deposicionais preponderantes e são resultantes da interação de diversos fatores tais como clima, aspectos geológicos, solos, relevo, cobertura vegetal e as diversas formas de uso e ocupação da terra (VERÍSSIMO et al.,1996).

Sthahler (1957) desenvolveu um método de análise dimensional e semelhança geométrica através de medidas de tamanho e de parâmetros geométricos lineares para agrupar bacias hidrográficas de maior similaridade geométrica. Esse método tem sido utilizado como auxiliar no processo de amostragem de bacias hidrográficas, que tenham comportamento hidrológico e características morfométricas semelhantes (CARVALHO et. al., 1990).

As análises morfométricas em geomorfologia, com a preocupação de medir as formas de relevo através de processos sistemáticos e racionais, tiveram grande sucesso no final do século XIX.. Esta fase inicial dos estudos morfométricos acabou sendo olvidada e suplantada pela expansão das novas concepções geomorfológicas oriundas do continente americano, e 
por outras tendências geormorfológicas já existentes na própria Alemanha (HENRI apud CHRISTOFOLETTI, 1969).

Cabe à morfometria, segundo Cooke e Doornkamp (1992) “... a mensuração e análise matemática da configuração da superfície terrestre e da forma e dimensões de sua paisagem”. Os autores afirmam que características morfométricas podem ser usadas na inferência sobre prováveis efeitos da interferência humana no sistema e nas estimativas das características de um rio da bacia numa área remota, necessária ao levantamento de recursos naturais, ou em partes não monitoradas de áreas já desenvolvidas (RAFAELI NETO, 1994).

A ordenação dos canais fluviais é o primeiro passo para a realização da análise morfométrica de bacias hidrográficas (análise real, linear e hipsométrica) (GUERRA \& CUNHA 1996).

Os critérios de ordenação dos cursos de água foram propostos, inicialmente, por Horton (1945) e modificado por Sthahler (1952). Para Sthahler (1952), os segmentos de canais formadores, sem tributação, são denominados de primeira ordem; da confluência de dois canais de primeira ordem surgem os segmentos de canais de segunda ordem que só recebem afluentes de ordem inferior (segmentos de canais de primeira ordem). Da confluência de dois segmentos de canais de segunda ordem surgem os segmentos de terceira ordem que recebem afluentes de ordens inferiores, no caso, segmentos de primeiras e segundas ordens (GUERRA e CUNHA 1995).

As diferentes formas de relevo presentes na superfície terrestre são oriundas da interação entre processos tectônicos, pedogenéticos e intempéricos, que atuam de forma diversificada nos diferentes materiais rochosos. As bacias hidrográficas, como um sistema individualizado, podem ser consideradas como fontes de dados relevantes para a obtenção de informações sobre a evolução do modelo da superfície da Terra. No intuito de se obterem dados quantitativos para diferenciar áreas homogêneas dentro de uma bacia hidrográfica utilizam-se o método da análise morfométrica, que consiste na caracterização de parâmetros morfológicos, tais como: densidade hidrográfica, densidade de drenagem, gradiente de canais, índice de sinuosidade, entre outro. Tais parâmetros explicitam os indicadores físicos da bacia, caracterizando suas homogeneidades (LANA, 2001).

Com o lançamento dos satélites da série LANDSAT, surgiu o interesse de avaliar o potencial dos seus produtos fotográficos na avaliação quantitativa da drenagem, quando comparados com outros produtos mais tradicionais, como é o caso das fotografias aéreas, em várias escalas e em várias apresentações. A drenagem, juntamente com as feições de relevo, são os elementos que mais se destacam ao serem observados com um par estereoscópico de 
fotografias aéreas, ou ao serem analisadas em um produto LANDSAT, dependendo da área de estudo (EPIPHANIO, et. al.1982).

A crescente utilização de Sistemas de Informação Geográfica (SIG), em estudos de natureza distintos, como a morfometria, tem mostrado a necessidade de análise comparativa entre produtos cartográficos gerados pela técnica dos SIG's e aqueles produzidos por métodos convencionais, em função dos recursos e da eficiência oferecida pela informática (CASTRO, 1995).

As técnicas cartográficas tradicionais, baseadas na utilização de mapas impressos, foram substituídas pela tecnologia da computação gráfica, a partir da facilidade de acesso ao computador. Atualmente é demandado que a cartografia forneça dados que auxiliem cada vez mais na tomada de decisões e no gerenciamento de operações correlatas (BARRIONVEVO, 1995).

A caracterização morfométrica de bacias é de grande importância para estudos ambientais, principalmente quando o ambiente em questão está sofrendo alterações em parte de seu curso d'água, pois eles desempenham papéis importantes dentro do ecossistema. Sendo assim, tornou-se necessário o estudo da Bacia Hidrográfica do Ribeirão Cachoeira, para que se conheçam suas condições morfométricas e que os dados obtidos contribuam para futuras ações de conservação e recuperação.

\section{Objetivos}

\section{Geral}

Quantificar os parâmetros morfométricos da Bacia Hidrográfica do Ribeirão Cachoeira, localizada no município de Nova Xavantina - MT.

\section{Específico}

Fazer a compartimentação das sub-bacias do Ribeirão Cachoeira;

Elaborar o Modelo Digital de Terreno (MDT).

Calcular os parâmetros morfométricos propostos: Densidade de Rios e Drenagem, Coeficiente de manutenção, Extensão do Percurso Superficial, Relação de Relevo, Comprimento do Canal Principal, Amplitude da Bacia, Gradiente de Canais e Índice de Sinuosidade

\section{Material e Métodos}




\section{Área de Estudo}

O estudo morfométrico foi desenvolvido na Bacia Hidrográfica do Ribeirão Cachoeira, tributária do rio Areões, esta bacia esta localizada nos municípios de Nova Xavantina e Campinápolis, entre as coordenadas $52^{\circ} 18^{\prime}$ e $52^{\circ} 48 \mathrm{~W}$; $14^{\circ} 28^{\prime}$ e $14^{\circ} 36^{\prime} \mathrm{S}$, conforme mostra a Figura 1.

$\mathrm{Na}$ região ocorrem duas unidades geomorfológicas marcantes, a Depressão do Araguaia e o Planalto dos Guimarães, com rochas metareníticas intercaladas por filitos, sendo o solo em sua maior parte do tipo Latossolo Vermelho-Amarelo distrófico e litólico distrófico, segundo Brasil (1981).

A vegetação da Bacia do Ribeirão Cachoeira é, predominantemente, de Cerrado SS, contendo arvoretas, geralmente, raquíticas e tortuosas, e um tapete gramíneo-lenhoso, além da mata de galeria, que envolve as margens dos córregos e rios com árvores de porte maior. (BRASIL, op. cit.)

A Bacia Hidrográfica do Ribeirão Cachoeira possui uma área de $359,81 \mathrm{~km}^{2}$, cultivada com soja, milho e pastagens, além da criação de bovinos que se destaca como a principal atividade produtiva dentro da bacia hidrográfica.

O clima da região é do tipo Aw, segundo a classificação de Köppen (VIANELO \& ALVES, 1991), predominante do tipo tropical, com duas estações bem definidas, um período seco e um período chuvoso. A precipitação média anual nos últimos treze meses é de 1.536 $\mathrm{mm}$, com médias de temperaturas em torno de $25,5^{\circ} \mathrm{C}$, sendo junho e julho o mês mais frio e setembro o mais quente, segundo dados dos anos de 1989 a 2001, coletados na estação meteorológica de Nova Xavantina. 

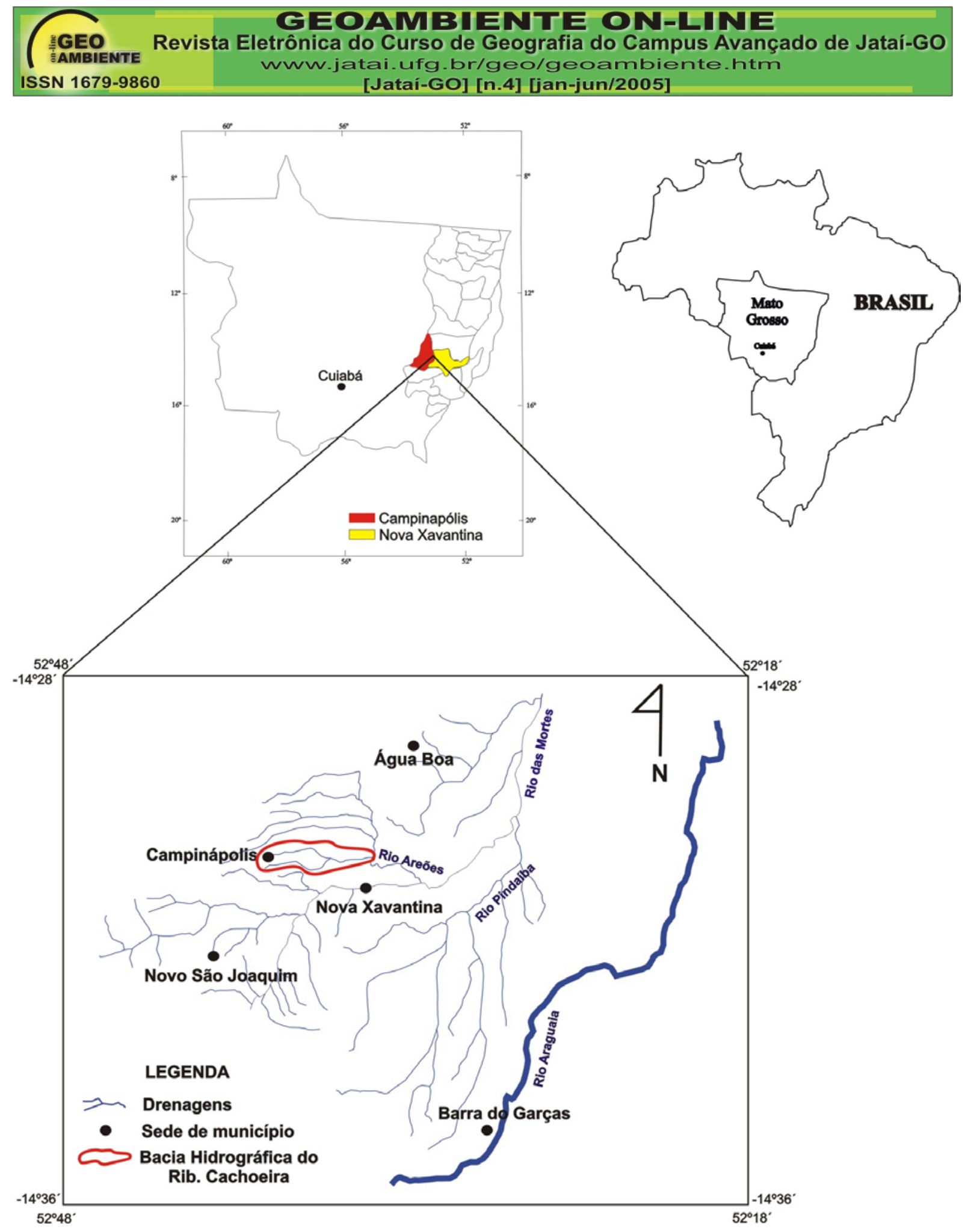

Figura 1. Mapa de localização da Bacia Hidrográfica do Ribeirão Cachoeira.

Para realização deste trabalho foram utilizadas as cartas topográficas de Nova Xavantina, folha SD-22-Y-A-VI (IBGE, 1980), e de Placa Nativa, folha SD-22-Y-B-IV (DSG, 1977), na escala de 1:100.000, com as quais foram digitalizadas as curvas de nível, as redes de drenagem e viária, utilizando-se uma mesa digitalizadora, formato A0, Marca Calcomp, e o software AutoDesk AutoCad 2000. 


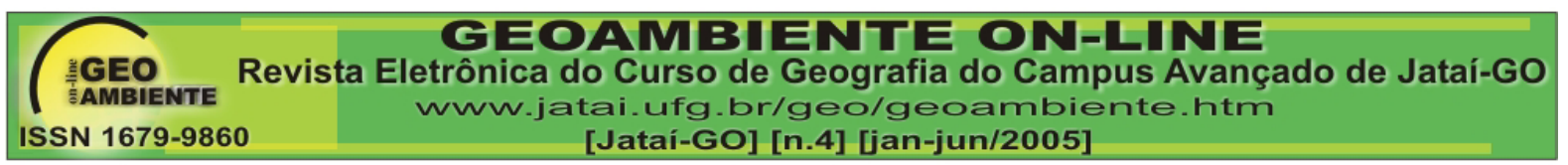

Os parâmetros, área da bacia, formato, distâncias e relações de relevo, foram calculados utilizando-se o software AutoCad. A carta topográfica foi utilizada para delimitação da bacia hidrográfica, de acordo com o padrão de drenagem e com as curva de nível, e ainda, para georeferenciar a bacia, no sistema de coordenadas geográficas, e fazer a sua compartimentação em microbacias.

O Modelo Digital de Terreno (MDT) foi gerado, por interpolação espacial das cotas altimétricas, pelo programa Surfer® for Windows (Golden Software, Inc.).

Foi utilizada também uma cena do satélite Landsat TM+ para a composição de uma imagem falsa cor (RGB 543) para auxiliar na identificação detalhada da drenagem, e ainda caracterizar o uso e ocupação do solo da bacia.

\section{Compartimentação da Área}

A compartimentação da área de estudo foi realizada com base na imagem de satélite e em observações de campo. O critério utilizado para cada compartimento foi à separação por microbacia.

\section{Levantamento da Rede de Drenagem}

O levantamento da rede de drenagem foi efetuado através da interpretação da imagem de satélite, considerando todos os canais de drenagens existentes. A fim de hierarquilizá-los, adotou-se a metodologia sugerida por HORTON (1945) e STRAHLER (1964).

A partir da hierarquização das drenagens, foram calculados os seguintes parâmetros:

\section{Densidade de Rios}

Por definição, a Densidade de rios $(D r)$ (canais/ $\mathrm{Km}^{2}$ ) é a relação existente entre o número de canais fluviais e a área da bacia de drenagem, e tem por finalidade comparar a freqüência de canais de água existentes em uma área de tamanho padrão, segundo HORTON apud VERISSIMO et al (1996). A densidade de rios representa o comportamento hidrológico de determinada área ou sua capacidade de gerar novos cursos de água, sendo expressa através da equação:

$$
\operatorname{Dr}=\frac{N}{A}
$$

onde $\mathbf{N}$ é o número total de cursos d'água e $\mathbf{A}$ a é área da bacia considerada $\left(\mathrm{Km}^{2}\right)$. 


\section{Densidade de Drenagem}

A Densidade de drenagem $(D d)$ (metros) ou a relação existente entre o comprimento total dos canais e a área da bacia. Esses parâmetros, definidos por HORTON (op. cit), refletem o grau de dissecação topográfica em paisagens elaboradas pela atuação fluvial, expressando em última análise, a quantidade disponível de canais de escoamento. Pode ser calculado pela equação:

$$
D d=\frac{L t}{A}
$$

onde Lt é o comprimento total de rios existentes em uma bacia (m).

\section{Coeficiente de Manutenção}

O índice de coeficiente de manutenção $(\mathrm{Cm})$ representa uma medida de textura, semelhante à densidade de drenagem. Para calculá-la, multiplica-se por 100 a recíproca do valor da densidade de drenagem (Dd), a fim de que os resultados sejam expressos $\mathrm{em} \mathrm{m}^{2} / \mathrm{m}$.

Este índice tem a finalidade de fornecer a área mínima necessária para a manutenção de um metro de canal de escoamento permanente. SCHUMM apud LANA (2001), considera como um dos valores numéricos mais importantes para a caracterização do sistema de drenagem, limitando sua área mínima requerida para o desenvolvimento de um canal.

O índice é calculado através da seguinte expressão:

$$
C m=\frac{1}{D d} \times 100
$$

\section{Extensão do percurso superficial}

A extensão do percurso superficial (Eps) (metros) representa a distância média percorrida pelas enxurradas antes de encontrar um canal permanente. O resultado obtido também serve para caracterizar a textura topográfica sendo calculada conforme CHRISTOFOLETTI (1969) pela equação:

$$
E p s=\frac{1}{2 D d}
$$

O valor obtido pelo cálculo da extensão do percurso superficial é similar, quanto à interpretação, ao coeficiente da manutenção. A diferença reside no fato de que no índice de coeficiente de manutenção o resultado é expresso em área mínima necessária para a existência 
de um canal, enquanto do índice da extensão do percurso superficial indica o comprimento do caminho percorrido pelas águas pluviais antes de se estabilizarem ao longo de um canal.

\section{Relação de Relevo}

A relação de relevo $(\mathrm{Rr})$ estabelece uma relação entre a diferença de altitudes máxima e mínima na bacia e o comprimento total do canal principal (SCHUMM apud LANA, 2001), ou seja:

$$
R r=\frac{\Delta a}{L}
$$

onde, $\Delta a=$ diferença entre as altitudes máxima e mínima (metros) e $L=$ comprimento do canal principal dentro de cada bacia ou sub-bacia (metros).

\section{Gradiente de Canais}

O gradiente de canais $(\mathrm{Gc})$ é a relação entre a altitude máxima e o comprimento do canal principal. Esse índice expressa a relação entre a cota máxima e o comprimento do canal principal expresso em porcentagem. A finalidade é indicar a declividade dos cursos d'água (HORTON, 1945).

$$
G c=\frac{A \max }{L}
$$

onde, $A_{\max }$ é a altitude máxima.

\section{Índice de Sinuosidade}

Este índice expressa a relação entre o comprimento do canal principal e a distância vetorial entre dois pontos extremos do canal principal. Relaciona o comprimento verdadeiro do canal (projeção ortogonal) com a distância vetorial (comprimento em linha reta) entre os dois extremos do canal principal. Valores próximos a 1,0 indicam que o canal tende a ser retilíneo. Já os valores superiores a 2,0 sugerem canais tortuosos e os valores intermediários indicam formas transicionais, regulares e irregulares. Sabe-se, entretanto, que a sinuosidade dos canais é influenciado pela carga de sedimentos, pela compartimentação litológica, estruturação geológica e pela declividade dos canais (LANA, 2001).

$$
I s=\frac{L}{d v}
$$


onde, Is é o Índice de Sinuosidade, L é o comprimento do canal principal e $d v$ é a distância vetorial entre os pontos extremos do canal principal

\section{Resultados e Discussão}

De acordo com a classificação apresentada por Farias (1984), a Bacia Hidrográfica do Ribeirão Cachoeira é do tipo dendrítica, a qual se caracteriza por mostrar uma ramificação arborescente em que os tributários se unem em uma só corrente principal formando ângulos agudos. Sua presença indica solos homogêneos e rochas sedimentares.

A tabela a seguir mostra o valor dos parâmetros calculados para a Bacia Hidrográfica do Ribeirão Cachoeira.

Tabela 1- Resultado dos parâmetros morfométricos

\begin{tabular}{|c|c|c|}
\hline Parâmetro Morfométrico & Total Bacia & Unidade \\
\hline Área Total da Bacia & 359,81 & $\mathrm{Km}^{2}$ \\
\hline Densidade de Rios & 1,183 & Canais $/ \mathrm{km}^{2}$ \\
\hline Densidade de Drenagem & 1,422 & Metros \\
\hline Coeficiente de Manutenção & 236,96 & $\mathrm{~m}^{2} / \mathrm{m}$ \\
\hline Extensão do percurso Superficial & 35,16 & Metros \\
\hline Relação de Relevo & 0,0079 & - \\
\hline Comprimento do Canal Principal & 90,447 & Metros \\
\hline Amplitude da Bacia & 364 & Metros \\
\hline Gradiente de Canais & 0,023 & $\%$ \\
\hline Índice de Sinuosidade & 5,569 & Metros \\
\hline Canais $1^{\text {a }}$ Ordem & 289 & - \\
\hline Canais $2^{\text {a }}$ Ordem & 102 & - \\
\hline Canais $3^{\mathrm{a}}$ Ordem & 27 & - \\
\hline Canais $4^{\mathrm{a}}$ Ordem & 5 & - \\
\hline Canais $5^{\mathrm{a}}$ Ordem & 2 & - \\
\hline Canais $6^{\mathrm{a}}$ Ordem & 1 & - \\
\hline
\end{tabular}

A bacia fica também caracterizada, por conter dois grandes compartimentos, a Bacia Hidrográfica do Ribeirão Cachoeira e a Sub-Bacia do Córrego Voadeira, conforme ilustra a Figura 02. 
IGEO Revista El GEOAMBIENTE ON-LINE

Eletronica do Curso de Geografia do Campus Avançado de Jataí-Go

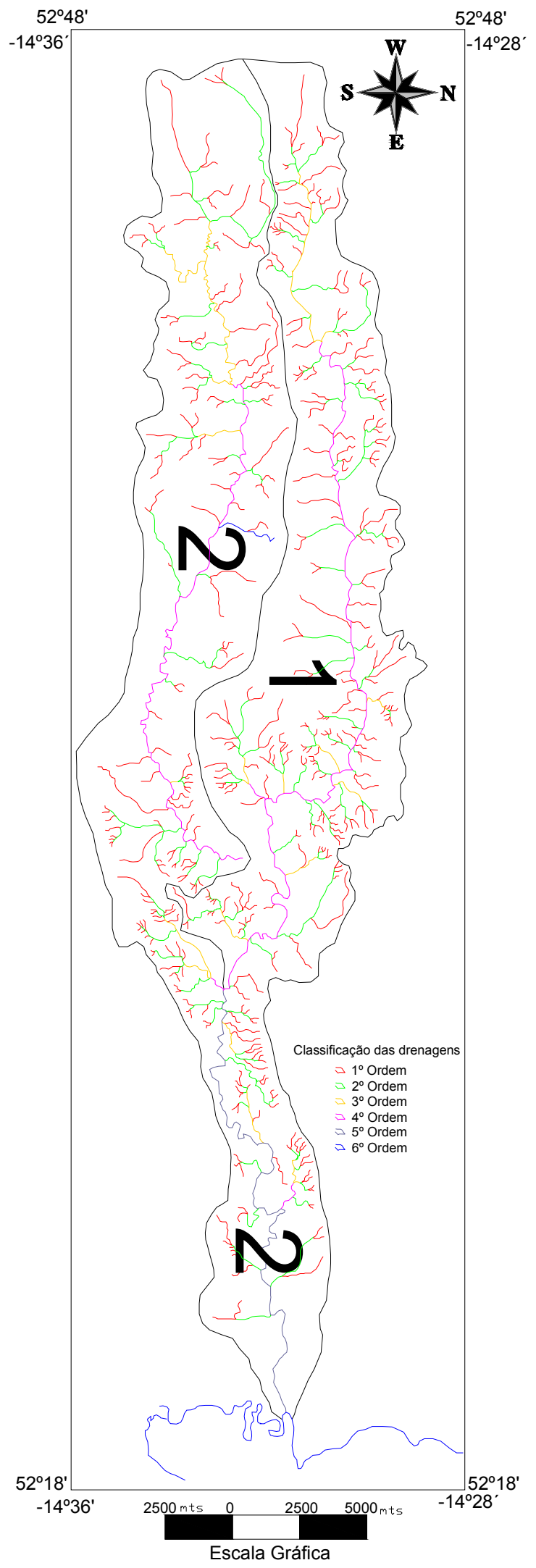

Figura 2. Compartimentação da Bacia Hidrográfica do Ribeirão Cachoeira. (1 - Sub Bacia do Córrego Voadeira, 2 - Bacia do Ribeirão Cachoeira). 


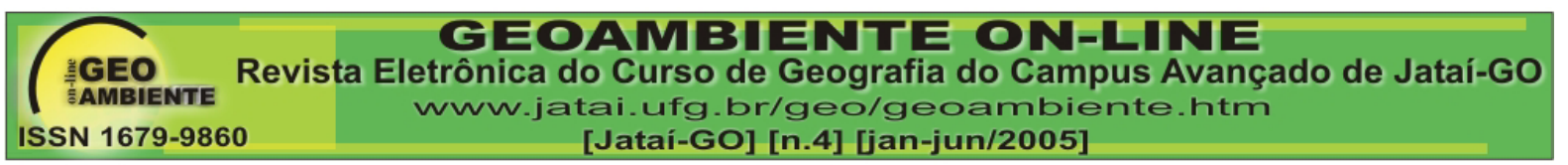

As drenagens se mostram de forma angulada (uma variante de bacias dendríticas), onde as falhas, fraturas e sistemas se unem em uma forma clássica. As águas, que vêm de pontos mais altos da bacia, formam comumente curvas fortes, formando ângulos grandes, e que os tributários são controlados pelas rochas. Estes ângulos de direção podem refletir um tipo específico de rocha, por exemplo, as rochas areníticas, evidentes dentro a bacia, que podem formar uniões paralelas, que posteriormente formam uniões mais agudas, conforme comenta Farias (1984).

A Densidade de Rios da Bacia Hidrográfica do Ribeirão Cachoeira foi de 1,183 Canais $/ \mathrm{km}^{2}$. Segundo Lana (2001), para valores acima de 2,00 Canais $/ \mathrm{km}^{2}$, a bacia tem uma grande capacidade de gerar novos cursos d'água, comparativamente temos um valor intermediário para a Bacia Hidrográfica do Ribeirão Cachoeira.

A Densidade de Drenagem na Bacia Hidrográfica do Ribeirão Cachoeira foi de $1,442 \mathrm{~m} / \mathrm{km}^{2}$, mostrando que a bacia apresenta em sua composição litológica, rochas de granulometria fina, como as rochas areníticas presentes na área, as quais possuem melhor permeabilidade, dificultando assim o escoamento superficial, influenciando na Densidade de Drenagem dentro da bacia.

Já o Coeficiente de Manutenção foi de $236,96 \mathrm{~m}^{2} / \mathrm{m}$, indica que a Bacia tem uma área relativamente boa para manutenção de seus canais, sendo que este valor fica dentro de uma média se comparadas a outras bacias. Para Cristofoletti (1969), o Coeficiente de Manutenção é um dos valores mais importantes para a caracterização do sistema de drenagens, onde o valor do índice representa a área mínima para um canal de primeira ordem, o que posteriormente dá origem às demais ordens de canais dentro de uma bacia.

A Extensão do Percurso Superficial, ou seja, a distância média percorrida pelas enxurradas antes de encontrar um canal permanente, foi de 35,16 metros. Para Cunha e Guerra (1995) a maior parte das observações comprovam a influência do escoamento superficial que está relacionada a cobertura vegetal. Isso então coloca peso muito grande na cobertura vegetal, como fator controlador do escoamento superficial.

Com a análise da imagem de satélite foi possível, além de caracterizar o uso e ocupação na bacia, também verificar a ausência da cobertura vegetal, fator este que facilita o impacto das gotas de chuva, fazendo com que os agregados se quebrem, crostas sejam formadas na superfície do solo, o que aumenta os efeitos do escoamento superficial, causando maior taxas de erosão. Para o valor obtido na Bacia Hidrográfica do Ribeirão Cachoeira, mostra que a bacia, por estar dentro de áreas agrícolas tem um processo de escoamento superficial acentuado, devido ao remanejamento de partes do subsolo para cima e vice e 


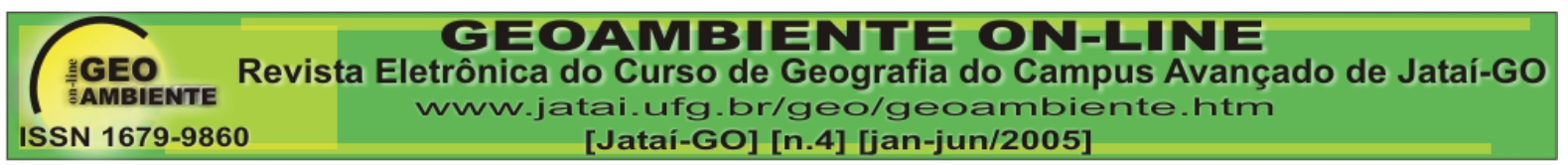

versa, fazendo com que a espessura do solo diminua, ficando assim suscetível à diminuição de matéria orgânica. A diminuição do teor de matéria orgânica no solo não só afeta sua fertilidade natural, mas também diminui sua resistência ao impacto das gotas de chuva, resultando, quase sempre, em aumento das taxas de escoamento superficial, que por conseqüência acarreta no aumento a extensão do percurso superficial.

A Relação de Relevo na Bacia Hidrográfica do Ribeirão Cachoeira foi de 0,0033 para a Sub-Bacia do Voadeira e 0,0046 constituindo uma bacia de relevo médio, ou seja, apresenta áreas de morros (relevo irregular) na sua nascente, a qual vai se abrandando até a foz, onde o relevo é plano.

Com relação à Amplitude da Bacia a mesma se mostrou bastante alta, a Sub-Bacia do Córrego Voadeira foi de $144 \mathrm{~m}$ e a da Bacia do Ribeirão Cachoeira foi de $220 \mathrm{~m}$. Segundo Fritz (2000), as curvas de nível existentes nas cartas topográficas permitem a confecção de mapas de declividades, o qual gera um importante subsídio para estudos ambientais, conforme demonstra a Figura 03.

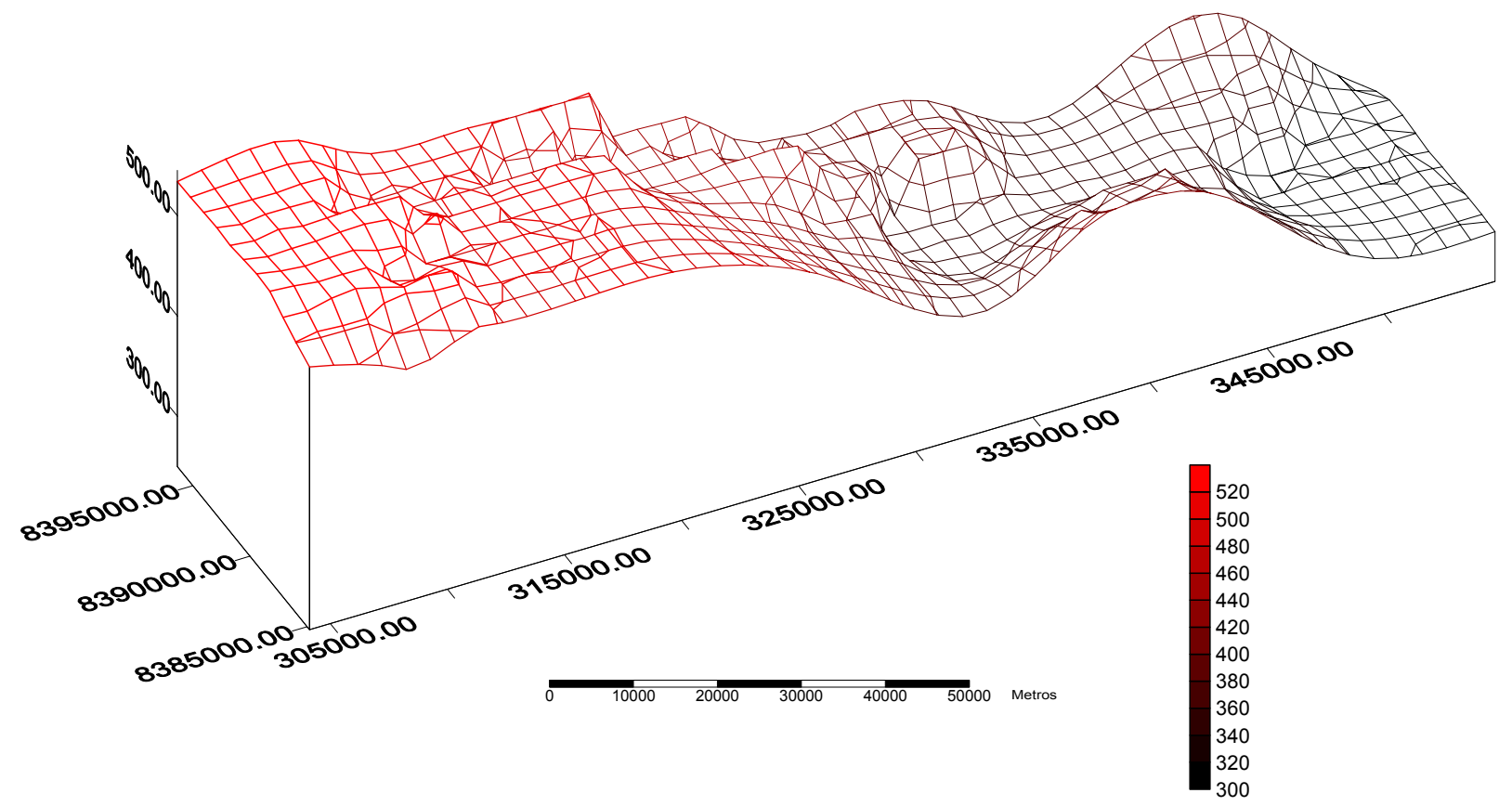

Figura 3. Modelo Digital de Terreno da Bacia Hidrográfica do Ribeirão Cachoeira, obtido através das Curvas de Nível.

O Gradiente de Canais da Bacia Hidrográfica do Ribeirão Cachoeira foi baixo, sendo que a Sub-Bacia do Córrego Voadeira apresentou um gradiente de 0,012\% e o da Bacia 
do Ribeirão Cachoeira foi de $0,011 \%$. Para Lana (2001), canais que apresentam valores médios de $0,90 \%$, tendem a possuir baixa declividade. Portanto a bacia do Ribeirão Cachoeira apresenta em geral muito baixa declividade no seu curso de águas. Como este valor representa uma média, isto não pode se empregar em alguns trechos, onde, por exemplo, existem quedas d'água, como ocorre na Cachoeira do Ribeirão Cachoeira, onde se forma uma queda d'água de aproximadamente 15 metros.

Outro parâmetro foi o Índice de Sinuosidade, o qual mostra a influência da carga de sedimentos, pela compartimentação litológica, estruturação geológica e pela declividade dos canais. O valor encontrado para a Sub-Bacia do Córrego Voadeira foi 3,994, indicando um índice de sinuosidade elevado, enquanto que para a Bacia do Ribeirão Cachoeira foi de 1,575, demonstrando um índice menor. Para Riccomini et al (2000), o valor de 1,5 divide arbitrariamente os rios de alto (maior que 1,5) e baixa (menor que 1,5) sinuosidade, a Bacia do Ribeirão Cachoeira foi então considera como de alta sinuosidade.

Para Schumm apud Cunha \& Guerra (1996), as diferentes sinuosidades dos canais são determinadas muito mais pelo tipo de carga detrítica do que pela descarga fluvial. Assim os canais meândricos relacionam-se aos elevados teores de silte e argila, e os canais anastomosados a uma carga mais arenosa, esse autor ainda faz referência à diminuição da sinuosidade pelo aumento da granulometria e da quantidade de carga detrítica.

De um modo geral a Bacia Hidrográfica do Ribeirão Cachoeira, teve seus índices morfométricos normais, se comparadas a outras bacias hidrográficas.

\section{Conclusões}

Com este trabalho pode-se concluir que:

- De acordo com os resultados, pode-se constituir uma base de dados, a fim de fazer futuras comparações, a fim de medir os impactos dentro da bacia;

- Devido à morfologia das drenagens, caracterizou-se a presença de rochas areníticas;

- A Bacia possui grande capacidade de gerar novos cursos d'água, de acordo com a relação área/número total de cursos d'água;

- Apresenta uma área relativamente boa para a manutenção de seus canais de drenagens;

- O Modelo Digital de Terreno se mostrou importante para avaliações da Bacia, pelo fato de que oferece uma maneira prática da visualização em 3D; 
- Apresenta um índice de sinuosidade irregular, determinado muito mais pelo tipo de carga detrítica do que pela descarga fluvial, devido em partes ao manejo solo com técnicas ultrapassadas.

\section{Referências Bibliográficas}

BARRIONVEVO, R. N. Metodologia de Conversão de Dados do AutoCad para o Idrisi.Relatório Final. FAPESP. Campinas-SP: Feagri, 1995. p. 26.

BRASIL. 1981. Ministério das Minas e Energia. Secretaria Geral. Projeto RADAMBRASIL, Folha SD 22. Goiás: geologia, geomorfologia, pedologia, vegetação, uso potencial da terra. Rio de Janeiro-RJ: Divisão de Publicação, v. 25 p. 636

CARVALHO, W. A.; FRANÇA, G. V. \& CURI, P. R. Aplicação de Análise Multivariada na Discriminação de Unidades de Solo Mediante Parâmetros Morfométricos de Bacias Hidrográficas, em Botucatu-SP. Revista Brasileira de Ciência do Solo. Campinas-SP, 1990, Vol, 14, p. 195-203.

CASTRO, J. F. M. Análise Comparativa entre Informações Morfométricas obtidas por Métodos Convencionais e por Métodos Digitais. Geografia. Rio Claro: UNESP, 1995, Vol. 20. p. 115-133.

CHRISTOFOLETTI, A. Análise Morfométrica das Bacias Hidrográficas. Campinas-SP, Noticiário Geomorfológico, 1969, Vol. 9, p.35.

EPIPHANIO, J. C. N.; FORMAGGIO, A. R. \& FILHO, M. V. Imagens RBV/Landsat-3 em Estudos Quantitativos da Rede de Drenagem, II Simpósio Brasileiro de Sensoriamento Remoto, Brasília - INPE, 1982, Vol. I, p. 285-292.

FARIAS, I. C. et alii. Guia para La Elaboracion de Estúdios Del Medio Fisico: Contenido y Metodologia. $2^{\circ}$ ed., Madri, Espanha. CEOTMA/MOPU, 1984. 572p.

FITZ, Paulo Roberto. Cartografia Básica. Canoas: LA SALLE, 2000. 171 p.

GUIMARÃES FILHO, H. A. \& CROSTA, A. P. Digitalização de Mapas. VII Simpósio Brasileiro de Sensoriamento Remoto, Curitiba, 1993, V. 2, p.351-358.

GUERRA, Antonio J. T. \& CUNHA, Sandra B. Geomorfologia: uma atualização de bases e conceitos. 2. ed. Rio de Janeiro: Bertrand Brasil, 1995. p. 472.

HORTON, R. E. Erosional development of streams and their drainage basins: hydrophysical approach to quantitative morphology. Geological Society of America Bulletin, 1945, 275-370 p. 
GEO Revista Eletrônica do Curso de Geografia do Campus Avançado de Jataí-Go ISSN 1679-9860

LANA, C. E.; ALVES, J. M. de P.; CASTRO, P.T.A. Análise Morfométrica da Bacia do Rio do Tanque, MG-BRASIL. REM. Ouro Preto-MG, 2001, Vol 54(2), p. 121-126.

RAFAELI NETO, Silvio L. Análises Morfométricas em Bacias Hidrográficas Integradas a um Sistema de Informações Geográficas. 1994.. Dissertação (Mestrado em Ciências Geodésicas), Universidade Federal do Paraná, Curitiba. $135 \mathrm{p}$

RICCOMINI, C.; GIANNINI, P. C. F. \& MANCINI, F. Decifrando a Terra/ organizadores: Wilson Teixeira (et al). São Paulo: Oficina de Textos, 2000.568 p

VERÍSSIMO, M. E. Z.; NOVO, E. M. L .M. \& VERÍSSIMO, C. U. V. Estudo da Bacia Hidrográfica do Rio Passaúna-PR, através de Parâmetros Morfométricos da Rede de Drenagem. Revista de Geologia. Fortaleza-CE, 1996, Vol. 9, p. 97-109

VIANELLO, R, L. \& ALVES, A. R. Meteorologia básica e aplicações. Viçosa: UFV, 1991, $449 \mathrm{p}$. 